IFAS Extension

\title{
Grandparents Raising Grandchildren: Guidance and Discipline ${ }^{1}$
}

Millie Ferrer-Chancy, Larry F. Forthun, and Angela Falcone ${ }^{2}$

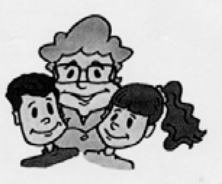

Goal: To provide grandparents with information for guiding children's behavior.

You have admirably accepted the role as the caregiver for your grandchildren. With this new role comes the responsibility of teaching your grandchildren appropriate behaviors or, in other words, guiding your grandchildren's behavior.

All children will misbehave at times. There's a good chance your grandchildren will have temper tantrums, talk back, or act inappropriately. It is important to know how to effectively respond to misbehavior.

There are basically two techniques parents use to change unacceptable behavior: punishment or discipline. The difference between punishment and discipline is often misunderstood. Punishing is the act of stopping the immediate behavior. Discipline is the act of teaching your child self-control and the consequences of her or his actions.

\section{Punishment}

In the minds of many parents, punishment means spanking. However, spanking is only one type of punishment. Scolding, bullying, threatening, or anything else intended to stop the misbehavior is also considered punishment. Punishment is a penalty used with children when their behavior is considered wrong. It gives them a sense of what not to do, but it does not teach them anything. It does not help children understand why their behavior is inappropriate and what appropriate behavior is. Note the following example scenarios.
House Rule: Be respectful to others by not hitting or name-calling.

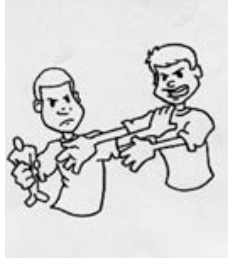

Situation: Your eight-year-old grandson is playing with a friend. $\mathrm{He}$ is arguing with him and calling him names.

Response: In an angry tone of voice, you yell at him to stop fighting.

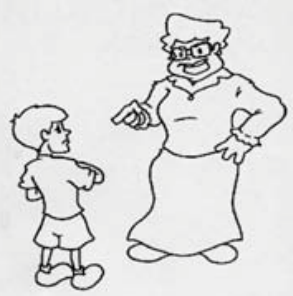

Your purpose: By doing this you attempt to stop the behavior.

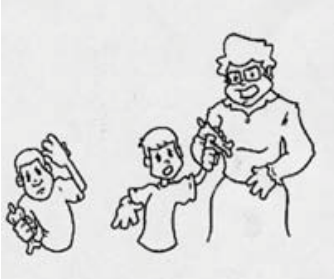

Outcome \#1: Your grandchild continues to misbehave. You scream louder at him and spank him in order to stop his misbehavior.

Outcome \#2: Your grandchild temporarily stops the misbehavior yet feels humiliated by your actions.

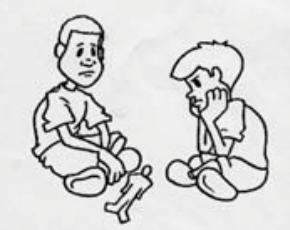

Unfortunately, he is likely to misbehave again because he didn't learn anything. Your grandchild is unaware of the effects of his behavior towards the other child.

1. This document is FCS2187, one of a series of the Department of Family, Youth and Community Sciences, Florida Cooperative Extension Service, Institute of Food and Agricultural Sciences (IFAS), University of Florida. Publication date: March 2002. Revised: August 2009. Please visit the EDIS Web site at http://edis.ifas.ufl.edu.

2. Millie Ferrer-Chancy, Ph.D.,interim dean, Florida Cooperative Extension Service, University of Florida; Larry F. Forthun, Ph.D., assistant professor, Family, Youth and Community Sciences, and Angela Falcone, former FYCS graduate student, Institute of Food and Agricultural Sciences, University of Florida, Gainesville, FL 32611 


\section{Discipline}

Discipline can be seen as a positive way of guiding grandchildren's behavior. It teaches them to act responsibly even when grandparents aren't around. Grandparents who are consistently warm and loving and who explain reasons for rules are more likely to see positive results. Grandchildren need reasonable limits and they need to know what will happen if they overstep their boundaries. Let's look at the same scenario handled from a guided-behavior approach.

House Rule: Be respectful to others by not hitting or name-calling.

Situation: Your eight-year-old grandson is playing with a friend. $\mathrm{He}$ is arguing with him and calling him names.
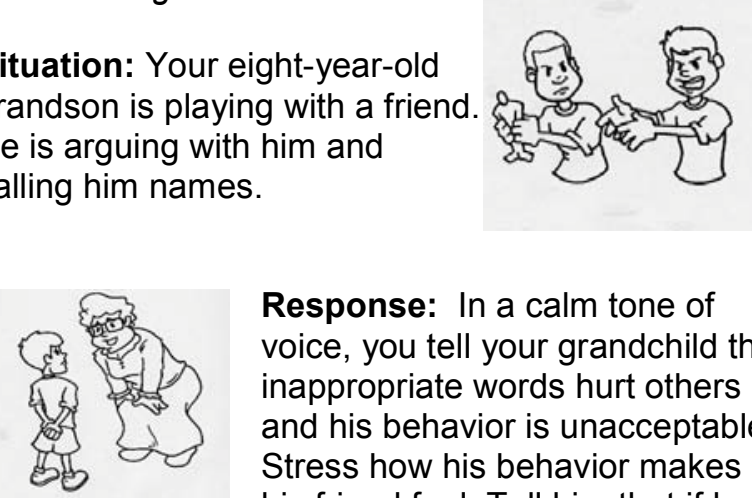

Response: In a calm tone of voice, you tell your grandchild that inappropriate words hurt others and his behavior is unacceptable. Stress how his behavior makes his friend feel. Tell him that if he continues this inappropriate behavior their playtime together will end.

Outcome \#1: Your grandchild continues to misbehave. You decide to end the play session, thus keeping your word. Following through with consequences is an effective part of discipline.
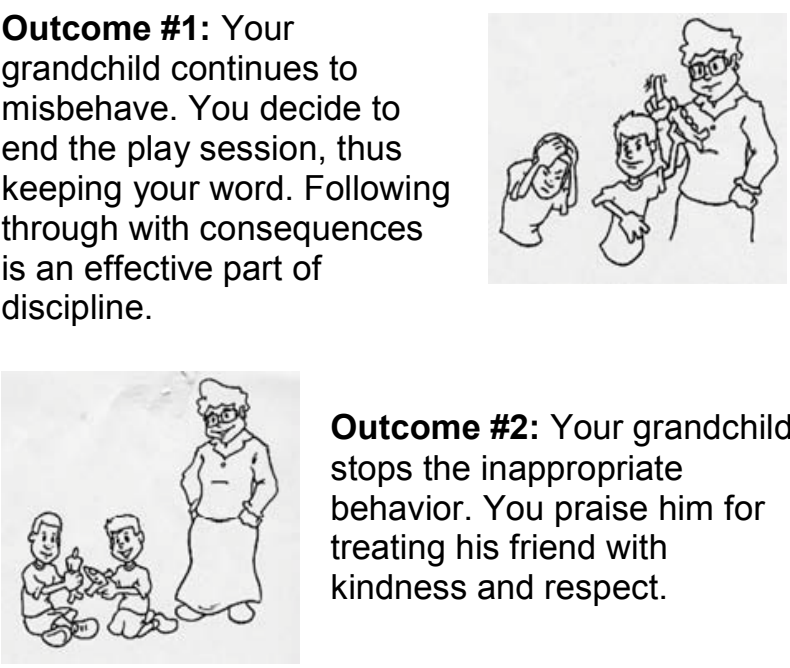

\section{Positive Ways for Guiding Children's Behavior}

Rules: Rules are guidelines set up to help children learn appropriate behaviors and keep them safe. They are clear, firm statements about the behavior you expect from your grandchild. It's important to understand that too many rules can confuse, frustrate, or overwhelm children. On the other hand, having too few rules can make children feel uncared for, lost, out of control, or unaware of what appropriate behavior is.

\section{Guidelines for Setting Rules}

1. Include children in making rules and consequences whenever possible. Children are more likely to follow rules they help create.

2. State rules impersonally. For example, state the rule as "Balls are for playing with outside," instead of "You can't play ball inside."

3. State rules positively. For example, "Friends can only come over when I am at home," not "You can't have friends over when I'm not here."

4. Have a plan of action if the rules are broken. When children know the consequences for breaking a rule, they learn to take responsibility for their own actions.

5. Rules need to be appropriate to your grandchild's age. Make sure that your grandchild understands the rules and that they match his abilities and skills.

6. Rules should be visibly displayed somewhere in the house (perhaps on the refrigerator). This can also be a family activity in which grandchildren write down rules/ expectations as they arise.

Consequences: There are two kinds of consequences grandparents can use to teach grandchildren to make responsible decisions about their behavior. One is called a natural consequence, and the other is a logical consequence.

- Natural consequences are a direct result of certain behaviors. For example, a child who does not want to eat dinner goes hungry. Whenever possible, use natural consequences. Natural consequences provide a way for children and teens to learn from their own experiences.

- Logical consequences are those that are imposed as a result of behavior but are logically related to the behavior. For example, dirty clothes not found in the hamper do not get washed. Therefore, the child must wash his own clothes.

By using natural and logical consequences, you are not blaming or judging the child. Instead, you are giving the child an opportunity to recognize a mistake and change behavior. 
Logical consequences differ from punishment in that logical consequences are directly related to what the child has done. On the other hand, punishment may have no logical relationship to what the child has done. For example, in spanking a child for not putting clothes in the hamper, there is no direct relationship between the behavior and the spanking.

\section{Test Your Knowledge}

In the following examples, read the situation and decide if each response is a natural consequence, logical consequence, or punishment.

\section{Five year old Nelly uses her crayons to color the walls.}

A. You tell her that crayons are used to color on paper not walls. You give her the materials needed to clean the wall. This is

B. You spank her and leave her alone in the room while she cries. This is

\section{You tell your twelve year old grandson, Robert, "It's going to get cold outside," but he leaves the house without a jacket.}

A. You tell him, "I told you so," and ground him for a week because he did not listen to you.

This is

B. Your grandchild gets cold and you don't say anything else to him about his decision to not take a jacket.

This is

\section{Sixteen-year-old Angela stays out later than the agreed upon curfew.}

A. You tell her that the next time she goes out, she has to come back an hour earlier because she was an hour late this time.

This is

B. You think to yourself that if she cannot respect the agreed upon time then she needs to suffer for her behavior. You tell her that she cannot be in the Drama Club with her friends anymore.

This is

When you use new discipline procedures, your grandchild's behavior may get worse before it gets better. Change comes slowly. With consistency and patience you can make the change. It is very important for you to stick to your plan. Don't give up!

\section{Other Resources}

Parenting 24/7: http://parenting247.org/

Keep Kids Healthy: http://KeepKidsHealthy.com/

\section{References}

Berk, L. (2000). Infants, children, and adolescents ( $3^{\text {rd }}$ ed.). Needham Heights, MA: Allyn \& Bacon.

Brooks, J. (2001). Parenting ( $3^{\text {rd }}$ ed.). Mountain View, CA: Mayfield Publishing Company

Ferrer, M. (1997). Guiding children's behavior. Childcare Centers Connections: National Network for Childcare Connection, 7, 2.

Ferrer, M. (1999). Success and the single parent: Positive parenting-Understanding children's behavior. University of Florida, Cooperative Extension. 8pp. FCS 2142

Ferrer, M. \& McCrea, S. (2000). Couples considering a blended family. University of Florida, Cooperative Extension. 3pp. FCS 2148.

Ferrer, M. \& McCrea, S. (2000). Let's talk about temper tantrums. University of Florida, Cooperative Extension. 3pp. FCS 2153

Forehand, R., \& Long, N. (1996). Parenting the strong-willed child. Chicago: Contemporary Books.

Hammer, T. \& P. Turner. (2001). Parenting in contemporary society $\left(4^{\text {th }}\right.$ ed. $)$. Boston: Allyn \& Bacon.

Oesterreich, Leslie. (2001). Ages \& stages: 9-11 years. lowa State University, University Extension. p.153. PM 1530i.

Turecki, S. (1989). The difficult child. New York: Bantam Books.

Williams, D. (2000). Grandparents raising our children's children. University of Idaho Cooperative Extension. Moscow, ID: Ag Communications. 